\title{
Clinical social work in Aotearoa New Zealand: Origins, practice, and future implications
}

\author{
Joanna Appleby ${ }^{1}$, Barbara Staniforth ${ }^{1}$, Caroline Flanagan ${ }^{2}$ and Clarke Millar ${ }^{2}$
}

\begin{abstract}
INTRODUCTION: Clinical social work is practised with individuals, groups and families in areas concerned with mental health and counselling for people's wellbeing. As a field of practice, it has been insufficiently researched and often not understood in Aotearoa New Zealand. This article provides an overview of clinical social work in Aotearoa New Zealand.

APPROACH: This is a theoretical article that discusses the development of social work, and clinical social work, in this country; attention is paid to professionalisation debates and registration. There is an overview of the social work training landscape and post-qualifying mental health specialisation options, with a brief discussion about the New Entry to Specialist Practice model for social workers. Theoretical underpinnings of clinical social work interventions are canvassed, including systemic models, recovery approaches, strengths-based models, indigenous models, narrative therapy, cognitive behavioural therapy and dialectical behaviour therapy. Four vignettes of clinical social work are presented, before a discussion about the future implications for clinical social work in Aotearoa New Zealand.
\end{abstract}

CONCLUSION: Clinical social workers have a range of knowledge and skills to work with people in mental distress. A challenge is issued to clinical social workers to continue to uphold social work values within multidisciplinary mental health services. The development of a clinical scope of practice in the context of recent mandatory registration for social workers is recommended.

KEYWORDS: Clinical social work; mental health; counselling; scope of practice

Defining "what social work is" has often presented challenges to the profession. At the time of writing (2020), the Aotearoa New Zealand Social Worker Registration Board (SWRB) is working with various stakeholders to consider defining an initial broad scope of generalist social work practice (SWRB, 2020). Within social work there exist many fields of practice, and also specialty areas of practice. In this theoretical article, we will explore the specialty of clinical social work, and what makes it particularly unique in Aotearoa New Zealand.

Our motivation in writing this article comes from each of our own experiences of practising clinical social work across a range of mental health service settings in Aotearoa New Zealand. We recognise that clinical social work is not always well understood within this country, and we have taken the opportunity to present and discuss this field of practice within the context of mandatory
1 University of Auckland

${ }^{2}$ Registered social workers

AOTEAROA

NEW ZEALAND SOCIAL WORK 32(4), 103-115.

CORRESPONDENCE TO: Joanna Appleby joanna.appleby@auckland. ac.nz 
registration and developing scope(s) of practice.

We begin by discussing the historical development of social work, the influence of te ao Māori (Māori worldviews), and the tensions that have influenced the professionalisation project of social work in this country. These have all shaped the construction of perspectives and practice of clinical social work. We then consider the training context, major theories, models and perspectives utilised in clinical social work. We have each presented a vignette of clinical social work practice from our practice setting and conclude with the implications and future focus for clinical social work in Aotearoa New Zealand.

While many aspects of this article apply to all social work practice, the particular focus here will be on clinical social work. The authors are all, or have been, employed within clinical settings. While we acknowledge that there has been a strong critique levelled against clinical social work, over its individualistic focus, its maintenance of the status quo, the idea that it moves social work away from its social justice function and may support a neoliberal agenda (see for example, Dalal, 2018; Payne, 2014; Specht \& Courtney, 1994), the focus of this article does not lie in a critique of clinical social work, but rather an initial exploration of the specialty in Aotearoa New Zealand.

\section{What is clinical social work?}

There is not a strong history of clinical social work in Aotearoa New Zealand, and at times the term has not been well understood. Clinical social workers often engage in more generalist tasks, while many social workers will engage in clinical skills. It is difficult to definitively ringfence clinical social work.

Briggs and Cromie (2009) have discussed clinical social work across both the Australian and Aotearoa New Zealand contexts, and note that it can also be difficult to distinguish clinical social work from other clinical roles within mental health practice. However, they offer a definition that clinical social work is "concerned about the social context and social consequences of mental health" with the purpose to "restore individual, family and community wellbeing, to promote the development of the client's power and control over their own lives, and to promote the principles of social justice" (Briggs \& Cromie, 2009, p. 222).

Clinical social workers in Australia can become Accredited Mental Health Social Workers (AMHSWs), providing mental health assessment and treatment through Medicare Australia (Australian Association of Social Workers, 2014). AMHSWs are recognised by the Australian Federal Government as an assessing authority of specialist mental health expertise. They are trained in a range of psychological interventions, which are delivered in a holistic manner that recognises the broader implications of mental illness on a person in their environment.

The National Association of Social Workers (NASW, 2020) in the United States of America (USA) defines clinical social work as "a specialty practice area of social work which focuses on the assessment, diagnosis, treatment, and prevention of mental illness, emotional, and other behavioral disturbances". Treatment modalities often include individual, group and family therapy and within the USA, clinical social workers must be certified or licensed to practice within a particular state.

The Council on Social Work Education (CSWE) in the USA provided a comprehensive definition of clinical social work in 2009:

The practice of clinical social work requires the application of advanced clinical knowledge and clinical skills in multidimensional assessment, diagnosis, and treatment of psychosocial dysfunction, disability, or impairment including emotional, mental, and 
behavioral disorders, conditions, and addictions. Clinical practice interventions include case formulation based on differential diagnosis and assessment of risks and vulnerabilities and those factors that produce and constrain the strengths and resilience found in the transactions among people, their communities, and the larger social environment. (CSWE, 2009, p. 2)

Clinical social workers in the USA must usually hold a Master of Social Work degree and Licensed Clinical Social Workers (LCSW) must also undertake many hours of supervised practice and often a clinical-level board examination. Clinical social workers can work in a number of different settings such as in private practice, health settings, community mental health centres (CMHCs), primary care, and in drug and alcohol treatment centres (NASW, 2020).

The USA Social Work Licensure (2020) website distinguishes between clinical and direct practice social work: "[t]he main difference between clinical and direct social workers is what each is legally allowed to do. All social workers can connect clients with resources and offer guidance through difficult situations, but only clinical social workers can provide counseling treatments". In Aotearoa New Zealand, the understanding of clinical social work and the associated legislation is less clear.

From previous definitions the authors propose that clinical social workers in Aotearoa New Zealand would be those involved in the assessment and treatment of mental distress, and/or involved in counselling or engaging in therapeutic work to enhance client wellbeing. Most clinical social workers would be situated within health settings, child and family counselling settings or within a small field of private practice. Much clinical social work practice occurs within the context of the district health board (DHB) public mental health system, but there are also social workers providing clinical roles in non-government agencies, such as being engaged with Multi Systemic Therapy within Youth Horizons Trust, sexual offender treatment at SAFE Network and family therapy and counselling within agencies such as Family Works.

\section{History and context}

Social work and, in particular, clinical social work, has been forged within the tensions inherent within the history of Aotearoa New Zealand. Professional social work training in Aotearoa New Zealand did not begin until 1950 with a two-year post graduate diploma in social sciences offered through Victoria University (Nash, 2001). Staffing for this programme was, for the most part, made up of academics from the United Kingdom or those with American training. They brought with them some knowledge of casework, and early training at Victoria often focused on individual or family treatment (McCreary, 1971). With around 12 graduates per year coming from this initial programme, the growing social work workforce was composed mainly of people who had obtained their social work qualifications overseas, or those without formal social work qualifications.

A Māori renaissance in the 1970s and 1980s brought with it a strong protest against colonising forces, which included those present within social work training, particularly its 'casework function'. British and American social work models were criticised for responding to individualistic western perspectives, for being racist and aligned with the State in maintaining the status quo (Ministerial Advisory Committee on a Māori Perspective for the Development of Social Welfare, 1986).

At the same time that this was occurring, social workers in health were leading the way in encouraging further professionalisation. An ongoing debate occurred within the then National Association of Social Work (NASW), now named Aotearoa New Zealand Association of Social Work (ANZASW), about the 
benefits of formal social work registration. While the debate about professionalisation and regulation was complex (Hunt, 2017), the two sides aligned generally between the health social workers (most of whom who had increasingly obtained academic qualifications) and the rest of the social work workforce. In that camp sat people who saw professionalisation equated with elitism, those who viewed professionalisation being antithetical to Māori collectivist values, and those who had no professional social work qualifications (Staniforth, 2010a).

From 1978 until 1998, a number of motions recommending that social workers require formal social work training, and/or registration were put forward at the NZASW Annual General Meetings. All were defeated. Throughout this time, there was also a growing commitment to biculturalism for social work, with the Association eventually developing both Māori and Tauiwi (nonMāori) caucuses, changing its name to the Aotearoa New Zealand Association of Social Work and developing a bilingual and bicultural code of ethics (Beddoe \& Randal, 1994; Fraser \& Briggs, 2016; NZASW, 1993).

The availability of social work training grew rapidly from the 1980s onward, with a growing workforce of qualified social workers. In response to earlier criticisms about its colonial heritage, social work programmes increasingly began to teach indigenous perspectives, and Māori, many who had previously been traumatised within their earlier education (Wikaira, participant contribution in Staniforth, 2010c), increasingly completed formal training. While there were some factions still opposed to registration, the notion of registration of social work became more palatable to several stakeholders, and in 2003 the voluntary Social Workers Registration Act was passed (Hunt, 2017). Since that time, the ANZASW, the Tangata Whenua Social Work Association, the regulator (the SWRB), and the Council of Social Work Educators of Aotearoa New Zealand all lobbied to make mandatory registration a requirement of social workers, and to have protection of the title 'social worker' (Hunt, Staniforth, \& Beddoe, 2019). In early 2019, mandatory registration of social workers was enacted through the Social Workers Registration Legislation Act (2019). For the first time, scopes of practice for social work will be defined. The first scope of practice will define a generalist social work practice (SWRB, 2020), with more specialised scopes of practice likely to follow over time.

\section{Clinical social work in Aotearoa New Zealand}

This history is significant in understanding the notion of clinical social work in Aotearoa New Zealand. There are several factors which have contributed to clinical social work not developing widely as a field of practice. There appears to be confusion about what the term means, and the title "clinical social worker" is not widely used by social workers.

The professionalisation debate has taken up much of the energy of the profession to date (Daniels, participant contribution in Staniforth, 2010c). Without a mandatory, legislated requirement for social workers to have a formal qualification, it has been difficult to argue for increased specialisms such as clinical social work. Additionally, clinical social workers have been seen as elitist, status-seeking, and involved in maintaining people in positions of oppression (Holden \& Barker, 2018; Specht \& Courtney, 1994). With its focus on individual treatment, it has also been criticised as having a western focus and of minimal relevance to Māori (Ministerial Advisory Committee on a Māori Perspective for the Development of Social Welfare, 1986).

As stated, there has been very little written or researched about clinical social work as a specific field of practice in Aotearoa New Zealand. What has been written has been more closely aligned with counselling in social work, rather than clinical social work (Booysen \& Staniforth 2017; Staniforth, 
2010a, 2010b, 2010c). The concepts of counselling and clinical social work are sometimes seen as being interchangeable.

\section{Education and training}

Over the past 60 years the education requirements for social work qualifications have gone from a two-year diploma, to a three-year degree, to a four-year degree, and degrees have mostly sat at an undergraduate level (Hunt et al., 2019). There is a twoyear first professional qualifying master's degree offered by some institutions, but it is also required by the SWRB to have a generalist orientation (Ballantyne et al., 2019). Post-qualifying masters and doctoral level qualifications have been research focused, with the authors having no knowledge of any social-work-specific clinical programmes being offered within the country. The majority of social workers who do identify as clinical social workers have either come from other countries with a clinical tradition, such as the USA, Canada or South Africa, have engaged in further training in particular modalities, or obtained further counselling qualifications (Booysen \& Staniforth, 2017).

Te Pou o te Whakaaro Nui (2020), the national workforce development centre for the mental health, addiction and disability sectors in Aotearoa New Zealand, has developed the New Entry to Specialist Practice (NESP) programme for allied health staff, including social workers, who are entering the field of mental health. The programme involves postgraduate study in mental health, along with a capped caseload, dedicated release time for study, and mentoring from within the clinical team. The course content includes mental health assessment and diagnosis and clinical interviewing skills. These programmes have been developed in recognition of the knowledge gap that exists between generalist qualifications and the specialist skills expected of social workers in the field of mental health (Te Pou o te Whakaaro Nui, 2020).
The recent report into enhancing the readiness to practise (R2P) of newly qualified social workers (NQSWs) in Aotearoa New Zealand recommended more support for newly qualified social workers (NQSWs) (Ballantyne et al., 2019; Hunt, Tregurtha, Kuruvila, Lowe, \& Smith, 2017). Recommendations around reduced caseload and opportunities for post-qualifying training fit well with the NESP model. Mental health knowledge was identified within the $\mathrm{R} 2 \mathrm{P}$ project as a common knowledge gap for NQSWs, and the NESP programme was discussed by one respondent as an effective learning model. Some DHBs have NESP coordinators who facilitate group supervision and additional training (Staniforth \& McNabb, 2004). This is aligned to the R2P Report about the importance of workplace induction, supervision and peer support for NQSWs (Ballantyne et al., 2019).

The NESP study programmes do not include in-depth training in therapeutic modalities, and are not social-work-specific. NESP participants must be employed in a setting where assessment, and therapeutic 'treatment' are undertaken, as the programmes require consideration of case studies and / or video feedback of real work with clients. Whether a social worker does complete the NESP programme is dependent on their employer, funding, and capacity within the service to support the NESP learning.

\section{Theoretical underpinnings, approaches and models of practice}

Clinical social workers bring a relational, contextual, holistic and strengths-based approach to mental health assessment and intervention. Like all social workers, they use a range of theories and models, including, but not limited to, anti-discriminatory theory, ecological theory, systemic models, recovery approaches, strengths-based, and indigenous models (NASW, 2020). In addition to these skills, they will likely have also undertaken training above their 
basic social work qualification in order to provide 'treatments' such as narrative therapy, cognitive behavioural therapy and dialectical behaviour therapy (Booysen \& Staniforth, 2017).

Systemic approaches such as Gitterman and Germain's (2008) ecological systems theory, provide a framework for understanding individuals within their environments. While systemic approaches are evident in much of generalist social work practices, Mendenhall and Frauenholtz (2013) argued that clinical social workers work at the micro, exo and macro levels in order to increase mental health literacy. From practice, we are aware of the Auckland Liaison Education Adolescent Programme (LEAP) programme, which was developed by a clinical social worker to provide a dedicated consultation, liaison and mental health training service to schools. Systemic approaches are also used by clinical social workers involved in wraparound services. In addition to the clinical functions of assessment and treatment, child and adolescent mental health services (CAMHS) have developed wraparound teams for work with families who have mental health needs and concurrent child protection agency involvement. Kirkwood (2014), a Māori clinical social worker from a CAMHS wraparound team, has discussed how the wraparound approach is complementary to the Treaty of Waitangi principles, with a focus on culturally competent and collaborative engagement with families. Other systemic approaches applied by clinical social workers include provision of family therapy, couples counselling, and multi-systemic therapy for families with children with behavioural challenges.

Clinical social workers also bring recovery and strengths-based approaches to clinical settings, and aim to reduce power inequality with clients, engaging in collaborative assessment and goal setting. They actively look for client strengths and natural resources (Booysen, 2017). Within multidisciplinary health settings, clinical social workers have the additional role of advocating recovery and strengths-based approaches within the dominant medical model. Consumer feedback has endorsed recovery approaches, and the Ministry of Health (2018) supports a recovery approach to mental illness. Recovery approaches are aligned with the social work values of empowerment, respect and protection of human rights.

There are a number of indigenous models of wellbeing that have been put forward in Aotearoa New Zealand. Māori models are generally characterised by a holistic approach and an understanding of the impact of spirituality and collective identity on wellbeing (Wratten-Stone, 2016). One of the most widely known models is Te Whare Tapa Whā, developed by Mason Durie (1994). Translating to 'the four-sided house', it is a holistic model that views wellbeing as the collective strength and balance of four sides of a house-taha tinana (physical health), taha whānau (family health), taha hinengaro (thoughts and feelings/mental health) and taha wairua (spiritual health).

Kaupapa Māori theory has evolved from a base of being Māori, of recognition and validation of Māori cultural world views, and challenging the dominance of western knowledge bases (Smith, 1999). There are some services in Aotearoa New Zealand that have developed kaupapa Māori services. These include a CAMHS team (Elder et al., 2009), Māori adaptation of a cognitive behavioural therapy intervention (Mathieson, Mihaere, Collings, Dowell, \& Stanley, 2012), and a primary mental health service using the Whare Tapa Whā model (Abel, Marshall, Riki, \& Luscombe, 2012). Social workers have been involved in each of these programmes.

International and Aotearoa New Zealand trained clinical social workers have also been influenced by narrative therapy (Burack-Weiss, Lawrence, \& Mijangos, 2017). David Epston and Michael White, social workers from Aotearoa New Zealand 
and Australia respectively, published the first text about narrative therapy (White \& Epston, 1990). The approach is based on the assumption that people experience problems when the stories of their lives, as told by themselves or others, do not represent their lived experience. The therapeutic process is collaborative and seeks to re-story the lives and experiences of the person, thus co-creating a new narrative (White \& Epston, 1990).

In Aotearoa New Zealand, one of the dominant psychological therapies offered in mental health services and private therapy is cognitive behavioural therapy (CBT). CBT is based on the premise that a person's thinking affects their emotional and behavioural responses (Beck, 2020). There are several criticisms of CBT, including its place within the positivist research paradigm, that it is deficit focused, that it has an individualistic approach that ignores social oppression (Payne, 2014) and that it has been a tool promoted by neoliberal forces (Dalal, 2018). CBT is practised by clinical social workers in Aotearoa New Zealand, although there is a lack of research into the way in which it is practised. Despite the multiple pressures exerted by neoliberal paradigms within agency settings, clinical social workers have the capacity to be strengths-based, culturally competent, and cognisant of the impact of the environment upon a person, and so it is hoped that CBT is practised in a way that aligns to those values (Gonzalez-Prendes \& Brisebois, 2012; Padesky \& Mooney, 2012).

Dialectical behaviour therapy (DBT) is a psychotherapy that includes individual therapy, skills group, and telephone coaching for people with emotional problems. Clinical social workers are involved in delivering this programme in mental health services and in a residential DBT programme in Aotearoa New Zealand (Cooper \& Parsons, 2010). We are aware that clinical social workers have been involved in adaptations of the DBT programme, including development of DBT-informed skills groups for Māori young people in secure youth justice facilities (Weenink, 2019), in secure care and protection residences, and in the delivery of schoolbased DBT in collaboration with school teaching staff. Cooper and Parsons (2010) have examined the social work values at play in DBT. They have drawn links between core social work skills and DBT strategies, such as the use of empathy and adapting a nonjudgmental stance, and suggest that clinical social workers who are trained in DBT are highly skilled and provide effective services in Aotearoa New Zealand.

\section{Vignettes}

We have provided four vignettes, representative of our areas of clinical social work practice. The first three are derived from various cases to provide composite vignettes. The final is a real case with a pseudonym used. The woman provided her permission to present this work. These vignettes illustrate the use of different therapeutic modalities in clinical social work, including systemic, narrative and strengthsbased approaches, as well as CBT and DBTinformed interventions.

\section{Youth forensic service vignette}

The first vignette is from Joanna Appleby, a Pākehā social worker who completed her BSW and MSW in Aotearoa New Zealand. Jo has postgraduate qualifications in child and adolescent mental health and CBT and completed training in DBT. Her example comes from a DHB-based youth forensic service context.

Damon was a 15-year old Cook Island boy who became involved in the youth justice system. Damon ended up being placed in a secure youth justice residence due to his offending. Jo met with Damon in the residence and formulated that his poor distress tolerance was perpetuated through difficulties with problem solving and coping skills, partly due to poor role modelling within his family and peer group. When Damon became emotionally 
distressed, he became physically agitated, experienced urges to kill himself, to use methamphetamine, or to engage in thrill-seeking offending. Jo worked with Damon within the residence, using a combination of CBT and DBT-informed approaches. There was a focus on increasing Damon's awareness of his own triggers, particularly loneliness, and paying attention to the physical sensations that accompanied those feelings. Damon practised problem solving, seeking social support, and managing his urges to engage in unhelpful behaviour. This work was complemented with visual aids and tangible reminders, given his poor verbal skills. Prior to him returning home, Jo worked with Damon's mother to teach the skills that Damon had learned, and to make a plan to manage his suicide risk with those skills. Further whole-family support was provided once Damon had returned home, and a multi-agency risk management plan was developed, including Oranga Tamariki and Youth Horizons Trust.

\section{Adult cognitive therapy centre vignette}

The second vignette is from Barbara Staniforth, who completed her BSW and MSW in Canada, and then undertook both CBT and DBT training in Aotearoa New Zealand. Barbara was seconded from a $\mathrm{CMHC}$ team to a university-based specialist cognitive therapy centre.

Kale was a 36-year-old man referred to the CBT Centre by his CMHC for low mood and suicidal ideation. Barbara undertook an initial assessment with Kale including a number of structured tools such as the Beck Depression, Anxiety and Hopelessness inventories (see Beck, 2020). A careful consideration of possible environmental factors that may be contributing to Kale's difficulties was made, with no outstanding issues noted. A tentative diagnosis of Major Depressive
Disorder was made. A safety plan was developed to address the suicidal ideation (with ongoing liaison with the CMHC team) and psychoeducation about CBT and depression was given. Over the weeks, Barbara taught Kale a range of CBT interventions including behavioural skills such as breathing, relaxation, exercise and diet and engaging in meaningful activity. When Kale's mood had improved slightly, cognitive interventions were provided through a structured thought record process. This revealed certain unhelpful thinking patterns that Kale was engaging in, and also some situations that he wanted to change. A process of cognitive restructuring was used to change thinking patterns and structured problem solving was used to change situations. Kale reported an improvement in his mood, and his Beck Depression Inventory scores were significantly improved. A relapse prevention plan was developed and Kale was discharged back to the CMHC after 12 weeks of treatment.

\section{Child and adolescent mental health service vignette}

The third vignette is from Caroline Flanagan, who completed her MSW in Scotland. She has also completed postgraduate training in child and adolescent mental health and training in CBT in Aotearoa New Zealand. Caroline's example comes from a DHB-based child and adolescent mental health service.

Sophie was a 15-year-old Pākehā girl living with her parents. She was referred to the DHB CAMHS service by her general practitioner with concerns around self-harm by cutting, low mood, suicidal thoughts and complete school refusal. The clinical social work intervention was based on a formulation that Sophie's presentation was based on anxiety, both for her and her parents. Caroline provided individual CBT for anxiety with Sophie. The CBT included 
graded exposure with a gradual return to school. Caroline also discussed practical distress tolerance and mindfulness skills with Sophie to minimise the self-harm. Sophie's suicidal thoughts resolved once her stress reduced. Caroline worked with Sophie's parents around managing their own anxiety and provided skills-based family sessions. Important parts of work with this family involved opening a narrative around their shared experience of anxiety, with a family systems informed understanding of Sophie's difficulties. Caroline also worked with the family to develop their understanding and use of emotional language to help them move from binary notions of 'bad behaviour'. The focus of the work was on the whole family system, helping the family to identify and utilise the skills required to manage anxiety and distress in helpful ways.

\section{Maternal mental health service vignette}

The final vignette is from Clarke Millar, who completed his Master of Applied Social Work and postgraduate study in Discursive Therapies in Aotearoa New Zealand. Clarke's example comes from a DHB-based maternal mental health service.

A midwife referred a 39-year-old Māori woman, Morgan, to the maternal mental health service in the days following the birth of her baby. This was Morgan's sixth baby; four of her older children were in the custody of child-protective services. Morgan was homeless, had an impending court date for assault charges, and her behaviour on the postnatal ward appeared to staff as 'psychotic'. Morgan was diagnosed by the team psychiatrist with a post-natal depressive disorder, a resolving mild psychosis with long-standing post-traumatic stress disorder. The clinical social work intervention involved individual counselling with Morgan and a groupbased therapeutic intervention. This was based on a trauma-informed formulation of Morgan and her situation. Clarke provided individual counselling to help Morgan to process her trauma within a strengths-based narrative framework. Morgan also participated in the Circle of Security parenting group, with an emphasis on validating the feelings of her children, as well as her own feelings. Clarke also worked alongside Morgan to reduce structural barriers. He engaged in social work interventions of addressing homelessness and advocating for culturally responsive approaches, including arranging for her Family Group Conference to be held on a marae. Clarke was also able to use his mental health knowledge to clinically justify a service response that was attuned to Morgan's relational needs in the context of her post-traumatic stress. This included advocating within the multidisciplinary team for service flexibility in order to provide continuity of care when Morgan was moving between service geographic boundaries.

These four vignettes demonstrate some of the theories, approaches and models used in working with individuals and their families to improve emotional, behavioural and mental wellbeing. While each of the vignettes shows the use of specialised clinical skills, the inherent holistic work with these people and their families is consistent with the overall ethos and aims of all social work practice.

\section{Future directions and challenges}

It is an exciting time for clinical social work in Aotearoa New Zealand, with an opportunity for the profession (including clinical social workers, health leaders, educators and the regulator) to define this area of practice. There are a number of possible future directions for consideration. These include continued commitment to the Treaty of Waitangi, the impact of mandatory registration and the opportunity to develop a clinical social work scope of practice. 
These all have the possibility of impacting the clinical social work role within multidisciplinary teams and other environments.

Clinical social work has been criticised in Aotearoa New Zealand, given its roots in western individualistic history. Its future, therefore, must include a revisioning of practice within a more collective framework and a commitment to the Treaty of Waitangi. The ANZASW bilingual and bicultural Code of Ethics asserts that social work practice is grounded in the articles of the Treaty (ANZASW, 2019). The Social Workers Registration Legislation Act (2019) requires that all applicants for registration are competent to practise social work with Māori as well as other cultural and ethnic groups. There is a challenge for all social workers to be culturally competent to work with Māori-within systems that may not support this. The public health system in Aotearoa New Zealand, where many clinical social workers are employed, is sector based, with siloed thinking and a medical model that focuses primarily on individuals (Government Inquiry into Mental Health and Addiction, 2018). However, Māori thinking can be characterised as asectoral and holistic regarding wellbeing (Ahuriri-Driscoll, 2016). Competence to work with Māori means that clinical social workers have a responsibility to shape services to be responsive to the needs of those they serve. This necessitates inclusion of whānau and Māori concepts of health within mental health services.

True commitment to the Treaty means that clinical social workers have a role in enhancing Māori access to mental health services that are culturally responsive. Alongside advocating for improved access, mental health services must be culturally welcoming and safe for Māori, with inclusion of Māori customs, explanatory models and having space to discuss incorporation of clinical and cultural interventions. All social workers also have a role in promoting Māori input into service delivery. The explicit commitment of social workers to the Treaty of Waitangi necessitates that these issues should be forefront in the minds of social workers in Aotearoa New Zealand.

As social work registration has just recently become mandatory in Aotearoa New Zealand (with a two-year phase-in period), it is timely to attend to the issue of scopes of practice, including the development of a clinical scope of practice that reflects the bicultural nature of this country. Scopes of practice are not yet defined in Aotearoa New Zealand, nor are the pathways to eligibility. It is not yet clear if scopes will require postgraduate study, or if there will be a funding structure to enable mandatory training. Specialist scopes are unlikely to be developed until after the two-year transition period for mandatory registration. This is an opportunity for social work stakeholders to participate in the defining of the roles, actions and entry pathways for scopes of practice.

A clinical scope of practice could help address some current issues for mental health social workers in Aotearoa New Zealand. One particular issue is that there is rarely a specific social work lens on postgraduate mental health programmes or within therapeutic training. For example, while there are social workers who have completed postgraduate training in CBT, it is up to the individual social worker to critically reflect on how to connect social work values with the CBT model. A clinical scope could assist in making explicit the social work approaches to various therapeutic modalities.

The Health Practitioners Competence Assurance Act (2003) provides a mechanism to ensure competence of health practitioners in Aotearoa New Zealand. Professional authorities must specify scopes of practice, qualifications must be prescribed, and professional registration is mandatory. The Act provides generic terms to provide a framework that can apply to all health practitioners. However, the Act does not cover social workers, as social work roles are not limited to health social work, hence 
social workers have specific legislation. With the advent of mandatory social work registration and scopes of practice, there may be regulatory parity with other disciplines under the Health Practitioners Competence Assurance Act (2003). It is hoped that this will enhance the credibility of clinical social work within the health field, which was one of the first drivers for social work registration.

In developing a clinical scope of practice, the Australian and USA definitions could be considered (Australian Association of Social Workers, 2014; CSWE, 2009). Work done by the National DHB Health Social Work Leaders Council (2017) in association with the ANZASW to develop a health scope of practice, may also be beneficial in developing a clinical social work scope of practice.

The authors propose that a clinical scope of practice includes some of the features from health social work colleagues, as well as overseas examples. An understanding and application of Māori models of wellbeing, as well as understanding of cultural explanatory models of mental health will also be important. While not being prescriptive about choice of therapeutic models, it would be necessary for a clinical social worker to have training and continuing professional development in a therapeutic modality, and be competent to deliver therapeutic interventions to individuals, families and groups. An understanding of human growth and development as well as an understanding of basic psychological principles and brain functioning would also be beneficial.

While some of these aspects are considered within qualifying programmes, many social workers have described feeling unprepared for their counselling roles (Staniforth, 2010c).

Within a context of commitment to the Treaty and increased professionalisation of social workers, a further challenge is the promotion of the clinical social work identity and voice within multi-disciplinary mental health teams. CMHCs in Aotearoa New Zealand have a case management model with specific disciplines, namely social work, nursing and occupational therapy, undertaking generic case management as key workers for allocated service users (Briggs \& Cromie, 2009). This model can result in loss of specific professional identity. The work done on developing a clinical scope of practice for social workers could assist in defining a social work role in mental health services.

There are challenges associated with multi-disciplinary teams, with competing frameworks and values (Frost, Robinson, \& Anning, 2005; Keen, 2016). Clinical social workers have the opportunity to use these environments to provide a critical perspective, to challenge the medical paradigm, and to advocate for service reform. Clinical social workers bring a holistic perspective to these teams, offering a social justice perspective, and a social model of mental health, alongside the dominant medical model. Within this context, clinical social workers also have a role in challenging the rigidity of service exclusion criteria, particularly when policies serve the needs of the service over the needs of those who use the service (Appleby, 2020). As mental health and wellbeing service demand continues to increase, there can tend to be a focus on limiting service delivery and tightening inclusion criteria as a solution. For clinical social workers who are committed to social justice and anti-discriminatory practice, an alternative approach may include macro-level advocacy for service funding, in order to improve service flexibility and responsivity.

\section{Conclusion}

We have attempted to provide an overview of clinical social work in Aotearoa New Zealand. A definition of clinical social work was provided, along with a presentation of the historical context of social work in this country. We have considered the evolution of education and theoretical underpinnings of clinical social work and provided four examples of clinical practice. 
Clinical social work in Aotearoa New Zealand is an evolving field of practice. There is more work to be done in defining a clinical scope of practice and developing social work clinical training pathways. Clinical social workers have the opportunity to shape these developments over the next few years, and to continue to strengthen social work's influence within mental health and wellbeing services in Aotearoa New Zealand.

Accepted 9 October 2020

Published 15 December 2020

\section{References}

Abel, S., Marshall, B., Riki, D., \& Luscombe, T. (2012). Evaluation of Tu Meke PHO's Wairua Tangata programme: A primary health initiative for underserved communities. Journal of Primary Health Care, 4(3), 242-248.

Ahuriri-Driscoll, A. (2016). Health policy, health inequalities and Māori. In J. Maidment \& L. Beddoe (Eds.), Social policy for social work and human services in Aotearoa New Zealand (pp. 137-149). Christchurch: Canterbury University Press.

Appleby, J. (2020). Social work and service improvement: An example from the first youth forensic forum. Aotearoa New Zealand Social Work Review, 32(1), 86-91. doi:10.11157/anzswj-vol32iss1id709

Aotearoa New Zealand Association of Social Workers. (2019). Code of ethics. Retrieved from https://anzasw. nz/wp-content/uploads/ANZASW-Code-of-Ethics-Final1-Aug-2019.pdf

Australian Association of Social Workers. (2014). Practice standards for mental health social workers. Retrieved from https://www.aasw.asn.au/practitioner-resources/ applying-for-accredited-mental-health-social-workerstatus-eligibility-for-medicare-provider-number/applyingfor-amhsw-status

Ballantyne, N., Beddoe, L., Hay, K., Maidment, J., Walker, S., \& Mayhew, Z. (2019). Enhancing the readiness to practise of newly qualified social workers in Aotearoa New Zealand (Enhance R2P): Report on phase two the readiness to practise of NQSWs. Ako Aotearoa The National Centre for Tertiary Teaching Excellence. Retrieved from https://ako.ac.nz/knowledge-centre/ enhancing-the-readiness-to-practise-of-newly-qualifiedsocial-workers/

Beck, J. (2020). Cognitive therapy: Basics and beyond (3rd ed.). Guilford Publications.

Beddoe, L., \& Randal, H. (1994). The New Zealand Association of Social Workers. The professional response to a decade of change. In R. Munford \& M. Nash (Eds.), Social work in action (pp. 21-36). Dunmore Press.

Booysen, P. (2017). Aotearoa New Zealand strengthsbased counselling practice framework for social work
(Unpublished doctoral dissertation). University of Auckland, NZ.

Booysen, P., \& Staniforth, B. (2017). Counselling in social work: A legitimate role? Aotearoa New Zealand Social Work, 29(1), 16-27. doi:10.11157/anzswj-vol29iss1id214

Briggs, L., \& Cromie, B. (2009). Mental health social work in Aotearoa New Zealand. In M. Connolly \& L. Harms (Eds.), Social work: Contexts and practice (2nd ed.), (pp. 222-233). Oxford University Press.

Burack-Weiss, A., Lawrence, L. S., \& Mijangos, L. B. (2017). Narrative in social work practice: The power and possibility of story. Columbia University Press. https://doi.org/http://dx.doi.org/10.7312/ bura17360.

Cooper, B., \& Parsons, J. (2010). Dialectical behaviour therapy: A social work intervention? Aotearoa New Zealand Social Work, 21(4), 83-93.

Council on Social Work Education. (2009). Advanced social work practice in clinical social work practice. Author.

Dalal, F. (2018). CBT: The cognitive behavioural tsunami: Managerialism, politics and the corruptions of science. Routledge.

Durie, M. (1994). Whaiora Māori health development. Oxford University Press.

Elder, H., Milne, M., Witehira, H., Mendes, P., Heslin, A. Cribb-Su'a, A., ... Kalra, V. (2009). Whakaora nga moemoea o nga tupuna - Living the dreams of the ancestors. Future planning in a Kaupapa Māori CAMHS team. Australasian Psychiatry, 17(1), 104-107.

Fraser, S., \& Briggs, L. (2016). Bi-culturalism and accountability: Fundamental changes in social work practice in Aotearoa New Zealand 1984 - 1990. Aotearoa New Zealand Social Work 28(1), 43-51.

Frost, N., Robinson, M., \& Anning, A. (2005). Social workers in multidisciplinary teams: Issues and dilemmas for professional practice. Child and Family Social Work, 10, 187-196.

Gitterman, A., \& Germain., C.B. (2008). The life model of social work practice: Advances in theory and practice. Columbia University Press. Gonzalez-Prendes, A. A., \& Brisebois, K. (2012). Cognitive-behavioural therapy and social work values: A critical analysis. Journal of Social Work Values and Ethics, 9(2), 21-33.

Government Inquiry into Mental Health and Addiction. (2018). He Ara Oranga: Report of the Government Inquiry into Mental Health and Addiction. Retrieved from www. mentalhealth.inquiry.govt.nz/inquiry-report/

Holden, G., \& Barker, K. (2018). Should social workers be engaged in these practices? Journal of EvidenceInformed Social Work, 15(1), 1-13. doi:10.1080/237614 07.2017.1422075

Hunt, S. (2017). The social work regulation project in Aotearoa New Zealand. Aotearoa New Zealand Social Work, 29(1), 53-64. doi:10.11157/anzswj-vol29iss 1 id370

Hunt, S., Staniforth, B., \& Beddoe, L. (2019). Establishing the qualification criteria for social worker registration in Aotearoa New Zealand: Conflict and compromise. Social Work Education, 38(7), 894-907. doi:10.1080/02615479. 2019.1593957

Hunt, S., Tregurtha, M., Kuruvila, A., Lowe, S., \& Smith, K. (2017). Transition to professional social work practice: the first three years. Advances in Social Work \& Welfare Education, 19(2), 139-154. 
Keen, M. (2016). Mental health social work. In K. Hay, M. Dale \& L. Cooper (Eds.), Social work in Aotearoa New Zealand: Exploring fields of practice (pp. 151-188). Massey University Press.

Kirkwood, T. (2014). The engagement phase of wrap around systems of care. Aotearoa New Zealand Social Work, 26(1), 3-9

Mathieson, F., Mihaere, K., Collings, S., Dowell, A., \& Stanley, J. (2012). Māori cultural adaptation of a brief mental health intervention in primary care. Journal of Primary Health Care, 4(3), 231-238.

McCreary, J. (1971). The school of science: Part two-The minions. The New Zealand Social Worker, 7(2), 41-50.

Mendenhall, A. N., \& Frauenholtz, S. (2013). Mental health literacy: Social work's role in improving public mental health. Social Work, 58(4), 365-368.

Ministerial Advisory Committee on a Māori Perspective for the Development of Social Welfare. (1986). Puao-te-atatu. The report of the Ministerial Advisory Committee on a Māori perspective for the Department of Social Welfare. Department of Social Welfare.

Ministry of Health. (2018). Mental health work at the Ministry. Retrieved from https://www.health.govt.nz/our-work/ mental-health-and-addictions/mental-health/mentalhealth-work-ministry

Nash, M. (2001). Social work in Aotearoa New Zealand: Its origins and traditions. In M. Conolly (Ed.), Social work in New Zealand: Contexts and practice (pp. 32-43). Oxford University Press.

National Association of Social Workers (NASW). (2020). Clinical social work. Retrieved from https://www. socialworkers.org/Practice/Clinical-Social-Work

National DHB Health Social Work Leaders Council. (2017). New Zealand health social work scope of practice. Retrieved from https://www.parliament. nz/resource/en-NZ/52SCSS_ADV_74844_786/ db2a3e8d648c85009d5be241b465f15fc3af46cf.

New Zealand Association of Social Workers. (1993). Code of ethics and bicultural code of practice. Author.

Padesky, C., \& Mooney, K. (2012). Strengths-based cognitive behavioural therapy: A four-step model to build resilience. Clinical Psychology and Psychotherapy, 19, 283-290.

Payne, M. (2014). Modern social work theory (4 ${ }^{\text {th }}$ ed). Oxford University Press.

Smith, L. (1999). Decolonising methodologies: Research and indigenous peoples. University of Otago Press.

Social Workers Registration Board. (2020). Scope of practice. Retrieved from https://swrb.govt.nz/scope-ofpractice-approach/

Social Workers Registration Legislation Act. (2019). Public Act, No. 3. Retrieved from http://www.legislation.govt.nz/ act/public/2019/0003/latest/DLM7396614.html

Social Work Licensure. (2020). Clinical versus direct practice social work. Retrieved from https://socialworklicensure. org/articles/clinical-vs-direct-services-social-work/

Specht, H., \& Courtney, M. (1994). Unfaithful angels: How social work has abandoned its mission. The Free Press

Staniforth, B. (2010a). Counselling in social work in Aotearoa/ New Zealand: The historical, political and socio-cultural evolution. Aotearoa New Zealand Social Work Review, 22(3), 3-14.
Staniforth, B. (2010b). Counselling in social work in Aotearoa New Zealand: Social workers' perspectives and practice. Aotearoa New Zealand Social Work Review, 22(3), 15-26.

Staniforth, B. (2010c). Past, present and future perspectives on the role of counselling in social work in Aotearoa New Zealand (Unpublished doctoral dissertation). Massey University, Auckland.

Staniforth, B., \& McNabb, D. (2004). Group supervision for new staff: A question of value. In L. Beddoe, J. Worrall, \& F. Howard (Eds.), Weaving together the strands of supervision: Conference proceedings of the supervision conference (pp. 147-152). Auckland, NZ: The University of Auckland.

Te Pou o te Whakaaro Nui. (2020). New entry to specialist practice: Allied mental health and addiction. Retrieved from https://www.tepou.co.nz/initiatives/new-entry-tospecialist-practice-allied-mental-health-and-addiction/48

Weenink, M. M. M. (2019). He waka eke noa at korowai manaaki: A process evaluation of a dialectical behaviour therapy-informed skills programme for young people in a secure youth justice residence (Unpublished master's thesis). Victoria University of Wellington, New Zealand.

White, M., \& Epston, D. (1990). Narrative means to therapeutic ends. W. W. Norton.

Wratten-Stone, A. (2016). Kaupapa Māori models of psychological therapy and mental health services: $A$ literature review. Te Whānau o Waipareira Trust. 